\title{
ATP synthase ecto- $\alpha$-subunit: a novel therapeutic target for breast cancer
}

\author{
Jian Pan ${ }^{1,2}$, Li-Chao Sun², Yan-Fang Tao ${ }^{1}$, Zhuan Zhou ${ }^{2,3}$, Xiao-Li Du ${ }^{2,4}$, Liang Peng ${ }^{2,5}$, Xing Feng ${ }^{1}$, Jian Wang ${ }^{1}$, \\ Yi-Ping Li', Ling Liu', Shui-Yan Wu', Yan-Lan Zhang ${ }^{1}$, Shao-Yan Hu', Wen-Li Zhao ${ }^{1}$, Xue-Ming Zhu', \\ Guo-Liang Lou ${ }^{1,6^{*}}$ and Jian $\mathrm{Ni}^{7^{*}}$
}

\begin{abstract}
Background: Treatment failure for breast cancer is frequently due to lymph node metastasis and invasion to neighboring organs. The aim of the present study was to investigate invasion- and metastasis-related genes in breast cancer cells in vitro and in vivo. Identification of new targets will facilitate the developmental pace of new techniques in screening and early diagnosis. Improved abilities to predict progression and metastasis, therapeutic response and toxicity will help to increase survival of breast cancer patients.
\end{abstract}

Methods: Differential protein expression in two breast cancer cell lines, one with high and the other with low metastatic potential, was analyzed using two-dimensional liquid phase chromatographic fractionation (Proteome Lab PF 2D system) followed by matrix-assisted laser desorption/time-of-flight mass spectrometry (MALDI-TOF/MS).

Results: Up regulation of $\alpha$-subunit of ATP synthase was identified in high metastatic cells compared with low metastatic cells. Immunohistochemical analysis of 168 human breast cancer specimens on tissue microarrays revealed a high frequency of ATP synthase $\alpha$-subunit expression in breast cancer (94.6\%) compared to normal (21.2\%) and atypical hyperplasia (23\%) breast tissues. Levels of ATP synthase expression levels strongly correlated with large tumor size, poor tumor differentiation and advanced tumor stages $(P<0.05)$. ATP synthase $\alpha$-subunit over-expression was detected on the surface of a highly invasive breast cancer cell line. An antibody against the ATP synthase $\alpha$-subunit inhibited proliferation, migration and invasion in these breast cancer cells but not that of a non-tumor derived breast cell line.

Conclusions: Over-expression of ATP synthase $\alpha$-subunit may be involved in the progression and metastasis of breast cancer, perhaps representing a potential biomarker for diagnosis, prognosis and a therapeutic target for breast cancer. This finding of this study will help us to better understand the molecular mechanism of tumor metastasis and to improve the screening, diagnosis, as well as prognosis and/or prediction of responses to therapy for breast cancer.

Keywords: Two-dimensional liquid phase chromatographic fractionation, ATP synthase a-subunit, Tissue microarray, breast cancer, monoclonal antibody

\section{Background}

Breast cancer is one of the most frequently diagnosed and deadly cancers, with an estimated incidence of 7.69.1/10 000 inhabitants worldwide per year [1]. For some decades, studies of molecular alterations in tumors have successfully elucidated some mechanisms of mammary

\footnotetext{
* Correspondence: lou115@sohu.com; ni_jian2008@163.com

'Department of Hematology and Oncology, Children's Hospital of Soochow University, Suzhou, 215003, China

${ }^{7}$ Translational Research Center, Second Hospital, The Second Clinical School, Nanjing Medical University, Nanjing, China

Full list of author information is available at the end of the article
}

carcinogenesis, progression and metastasis, and identified key genes such as ERBB2, TP53, CCND1, BRCA1 and BRCA2 [2,3]. Although the survival of patients has increased over the last decades due to screening programs and considerable progress in post-operative adjuvant systemic therapies (hormone therapy and chemotherapy) targeting hormonal receptors and the ERBB2/HER2 receptor $[1,4,5]$, many patient deaths still occur after metastatic relapse. Prognostic markers currently accepted for clinical use, such as nodal status, tumor size, histological grade, steroid receptor status 
and others do not adequately identify patients at an early stage, increasing the risk of progression and metastasis [6]. Therefore, additional prognostic biomarkers for the clinical management of breast cancer patients are needed.

High-throughput genomic and proteomic techniques provide unprecedented opportunities to tackle the complexity of breast cancer $[3,7,8]$. A combination of biomarkers will likely be more sensitive and specific than a single biomarker to reflect the true heterogeneity of disease, more reliable for screening, diagnosis, prognosis and prediction of therapeutic responses, and more useful for finding new therapeutic targets [9]. Among the currently available techniques, proteomic analysis by two-dimensional mass spectrometry (2DE-MS) permits the screening of thousands of modified or unmodified proteins simultaneously, becoming increasingly popular for identifying biomarkers for early detection, classification and prognosis of tumors, as well as pinpointing targets for improved treatment outcomes $[8,10]$. A relatively newcomer to analytical proteomics is the commercial instrument PF 2D from Beckman Coulter, which uses chromatographic focusing to separate intact proteins in the first dimension by pI (from 8.5 to 4.0 ) and, in the second dimension, by reversed phase chromatography, which separates proteins based on hydrophobicity. Thus, the precise detection of isoforms and/ or proteins with post-translational modifications that alter the $\mathrm{pI}$ and/or hydrophobicity is enhanced.

In the present study, we conducted proteomic analysis on two breast carcinoma cell lines, MCF-7-H and MCF7 , with different metastasis potentials, by 2D liquid phase chromatographic fractionation using the PF 2D system $[11,12]$, followed by matrix-assisted laser desorption/time-of-flight mass spectrometry (MALDI-TOF/ MS), tissue microarray (TMA), immunological and functional analysis. One of the highly over-expressed proteins was identified as the $\alpha$-subunit of ATP synthase. ATP synthase is responsible for ATP production in oxidative phosphorylation and can work in reverse as a proton pumping ATPase $[13,14]$. ATP synthase expression is believed to be localized exclusively to mitochondria where it generates most cellular ATP. However, ATP synthase components have recently been identified as cell-surface receptors for apparently unrelated ligands in the course of studies carried out on angiogenesis [15-17], lipoprotein metabolism [18], innate immunity [19], hypertension [20] or regulation of food intake [21] by immunofluorescence, biochemistry and proteomics analyses [15]. Its molecular mechanism, function and significance have not been fully established. We detected the expression of ATP synthase $\alpha$-subunit protein by immunohistochemistry (IHC) in different human tumor samples, including breast cancer, hepatocellular carcinoma, colon cancer and prostate cancer. As ATP synthase $\alpha$-subunit was highly over-expressed in $94.6 \%$ of breast cancer samples tested, the present study is focused on the expression, functional implication and potential involvement of ATP synthase in the progression and metastasis of breast cancer.

\section{Methods}

\section{Cell culture conditions}

The breast cancer cell line MCF-7 (a gift from Zhi-Hua Yang, Chinese Academy of Medical Sciences, Peking Union Medical College, Beijing, China) was cultured in RPMI 1640 supplemented with 10\% fetal bovine serum (FBS). The highly invasive breast cancer cell line MDAMB-231 and the immortalized human breast epithelial cell line MCF-10F were purchased from American Type Culture Collection (ATCC, Manassas, VA). MDA-MB231 cells were cultured in DMEM medium supplemented with $10 \%$ FBS. MCF-10F cells were cultured in Ham's F12 medium supplemented with $10 \%$ FBS and 20 $\mu \mathrm{g} / \mathrm{ml}$ of epidermal growth factor. All cells were maintained at $37^{\circ} \mathrm{C}$ and $5 \% \mathrm{CO}_{2}$.

\section{Selection of a invasive subline from MCF-7 cells}

MCF-7 cells were seeded on a Matrigel (Becton Dickinson, Franklin Lakes, NJ) coated, $8 \mu \mathrm{m}$-pore transwell (Costar, Cambridge, MA)[12,22,23]. Twenty-four hours later, cells that had invaded to the other side of the trans well membrane were collected, expanded and then re-seeded into another Matrigel coated trans well. Such selection rounds for highly invasive cells were repeated six times, resulting in a highly invasive subline designated as MCF-7-H.

\section{2-D liquid chromatography and MALDI-TOF/MS analysis}

The Proteome Lab PF 2D two-dimentional liquid chromatography system (Beckman Coulter, CA, USA) consists of 1 st dimension chromatofocusing separation based on pI and 2nd dimension reverse-phase chromatography separation based on hydrophobicity. Chromatofocusing was carried out on the chromatofocusing column by mixing two buffers with different $\mathrm{pH}$ levels,

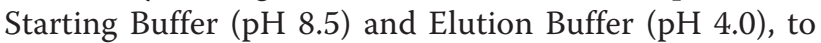
create a linear $\mathrm{pH}$ gradient from 8.5 to 4.0 , which was followed by wash buffer $(1 \mathrm{M} \mathrm{NaCl})$. Cell lysates $(2 \mathrm{mg})$ of MCF-7-H and MCF-7 with different metastasis potentials were injected onto the chromatofocusing column equilibrated for $130 \mathrm{~min}$ at $0.2 \mathrm{ml} / \mathrm{min}$ with the proprietary starting buffer including urea and a reducing agent at $\mathrm{pH}$ 8.5. Fractions were collected at $0.3-\mathrm{pH}$ intervals, and each fraction (200-500 $\mu \mathrm{l})$ was sequentially analyzed by reverse-phase HPLC. Proteins were separated at a flow rate of $0.75 \mathrm{ml} / \mathrm{min}$ on a non-porous C18 reverse phase column using $3.33 \% \mathrm{~B} / \mathrm{min}$ linear 
gradient in which solvent $\mathrm{A}$ was $0.1 \%$ aqueous trifluoroacetic acid and solvent B was $0.08 \%$ trifluoroacetic acid in acetronitrile. The different proteins were collected and digested with trypsin and analyzed by MALDITOF/MS.

\section{Patient selection and TMA}

Breast cancer TMAs were purchased from Shanghai Hujing Biotech Co., Ltd, China and Cybrdi Inc., USA, which contained duplicates of 194 human breast cancer tissues and 15 normal breast tissues with a diameter of $1.0 \mathrm{~mm}$. In addition, we collected 13 atypical hyperplasia of breast tissues and 18 normal breast tissues between 2007 and 2010 from the Cancer Institute (Hospital), Chinese Academy of Medical Sciences, Peking Union Medical College, Beijing, China. Ethical approval was provided by the Chinese Academy of Medical Sciences Cancer Hospital Ethics Committee. None of the patients received any neoadjuvant therapy prior to surgery. Prior patient consent and approval from the Institute Research Ethics Committee were obtained before we used these clinical materials for research purposes. Samples of normal tissues were taken from morphologically normal areas surrounding diseased tissue. Patients who received chemotherapy or radiotherapy before surgery were excluded. Samples with missing and invalid dots were also excluded. Therefore, in this study 168 female breast cancer patients (ranging in age from 31 to 82 , with a mean of 58 years), 13 atypical hyperplasia and 33 normal breast tissues were analyzed. All surgically obtained tissues were fixed in $4 \%$ formalin and processed routinely. The tumors were classified according to the Pathological Tumor-Node-Metastasis (pTNM) system (sixth edition). The pathologic features examined included histological subtype, tumor size, primary tumor stage and regional lymph node involvement. The microscopic slides from all specimens were reviewed by at least two pathologists and one American Society for Clinical Pathology certified specialist in immunology. Table II summarizes the clinical pathological parameters analyzed in this study.

\section{IHC analysis}

IHC was performed on $5 \mu \mathrm{m}$ thick paraffin sections of tissues and breast cancer TMA. All slides were deparaffinized in xylene and rehydrated in graded alcohols. For antigen retrieval, slides were immersed in $0.01 \mathrm{M}$ citrate buffer, $\mathrm{pH}$ 6.0, and boiled for $10 \mathrm{~min}$ in a microwave oven. Endogenous peroxidase was blocked in $0.3 \%$ $\mathrm{H}_{2} \mathrm{O}_{2}$ in PBS for $20 \mathrm{~min}$. To reduce non-specific binding, sections were pre-incubated in normal goat serum. The anti-ATP synthase $\alpha$-subunit mouse monoclonal antibody (mAb) (7H10-BD4, $1 \mu \mathrm{g} / \mathrm{ml}$, Invitrogen, A21350) was incubated on the tissues overnight in a humidified chamber at $4^{\circ} \mathrm{C}$. Subsequently, incubation of the samples with anti-mouse peroxidase-conjugated antibody was performed at room temperature for 30 min using a Power Vision Homo-Mouse IHC kit (ImmunoVision Technologies, Daly City, CA). Hematoxylin (Sigma) was used for counterstaining. Positive controls were included in each staining series. ATP synthase $\alpha$-subunit immunopositivity was scored as follows: 0 , no staining or sporadic staining in $<5 \%$ of tumor cells; 1 , weak and sporadic staining in $5-25 \%$ of tumor cells; 2, weak staining in 26-50\% of tumor cells; 3 , strong diffuse cytoplasmic and membrane staining in 26-50\% of tumor cells; and 4, strong, diffuse cytoplasmic staining and membrane staining in $>50 \%$ of tumor cells. For statistical analysis, negative (0), intermediate $(1+$ and $2+)$ and strongly $(3+$ and $4+)$ stained groups were created. Samples were evaluated under light microscopy by two independent pathologists and one American Society for Clinical Pathology certified specialist in immunology without prior knowledge of the patients' clinical data.

\section{Immunofluorescence analysis of breast cell lines}

MDA-MB-231 and MCF-10F cells were grown on glass cover slips and stained with the anti-ATP synthase $\alpha$ subunit antibody as described previously [24]. Briefly, MDA-MB-231 and MCF-10F cells were washed with PBS several times before fixation with 4\% Para formaldehyde. A sample was permeated with $100 \%$ ethanol for $5 \mathrm{~min}$ at room temperature as a positive control. Cells were then incubated overnight with the anti-ATP synthase $\alpha$-subunit mouse mAb $(1 \mu \mathrm{g} / \mathrm{ml})$ at $4^{\circ} \mathrm{C}$ and then washed twice in PBS. Subsequently, immunostaining was carried out for $1 \mathrm{~h}$ in the dark with a secondary antibody against mouse IgG2a conjugated to Alexa Fluor 488 (1:200, Molecular Probes) in staining buffer. Samples stained with the isotype mouse IgG2b antibody served as negative controls. The nuclei were labeled with PI (Propidium iodide). After final washings, the cells were mounted and analyzed using a Zeiss LSM-410 (Switzerland) confocal microscope at a magnification of $600 \times$.

\section{Flow cytometry analysis of breast cell lines}

MCF-7, MCF-7H, MDA-MB-453, MDA-MB-231 and MCF-10F cells were incubated at $20^{\circ} \mathrm{C}$ for $1 \mathrm{~h}$ in PBS, $\mathrm{pH} 7.4$, containing $1 \%$ bovine serum albumin (BSA) plus primary mAbs in order to analyze cell-surface expression of ATP synthase $\alpha$-subunit. The cells were then washed in PBS plus $1 \%$ BSA and incubated at $20^{\circ} \mathrm{C}$ for 30 min with a goat antibody against mouse IgG conjugated to Alexa 488 (1:200) and washed three times. A mouse IgG antibody served as negative controls. Propidium iodide was added to exclude the dead cells before 
analysis on a Coulter XL 4C flow cytometer (BeckmanCoulter).

\section{Cell proliferation assay}

MDA-MB-231 were plated at a density of 5,000 cells/ well in DMEM media depleted of FBS overnight to allow the cells to become quiescent, and MCF10F cells were likewise plated in Ham's F12 medium supplemented only with $20 \mu \mathrm{g} / \mathrm{ml}$ of epidermal growth factor [25]. Fresh media were added to the wells along with the anti-ATP synthase $\alpha$-subunit antibody Mab9E10 (10 $\mu \mathrm{g}$ / $\mathrm{ml}, 50 \mu \mathrm{g} / \mathrm{ml}, 100 \mu \mathrm{g} / \mathrm{ml})$. After every $24 \mathrm{~h}, 10 \mu \mathrm{l} \mathrm{CCK-}$ 8 (Dojindo, Kumamoto, Japan) were added to the cells, which were then incubated for $2 \mathrm{~h}$ at $37^{\circ} \mathrm{C}$. The absorbance, used to calculate the percent proliferation of the cells, was measured on a Thermo max plate reader at a wavelength of $450 \mathrm{~nm}$ according to the manufacturer's specifications. The MAb9E10 functional mAb generated against cell surface ATP synthase $\alpha$-subunit was reported previously [26]. Briefly, hybridoma cells secreting $\mathrm{mAb}$ against ATPase were produced by polyethylene glycol-mediated fusions and screened by ELISA. Specificity of the mAb was demonstrated by immunofluorescence and confocal imaging, as well as flow cytometry analysis.

\section{Cell migration and invasion assays}

Invasion assays were performed in trans well membrane filter inserts in 24-well tissue culture plates (BD Labware, Bedford, MA) as described previously [12]. Briefly, the trans well membrane filter inserts in a 24-well tissue culture plate contained $6.5 \mathrm{~mm}$ diameter, 8 - $\mu \mathrm{m}$ pore size, $10-\mathrm{nm}$ thick polycarbonate membranes. The lower surface of the porous membrane was coated with $10 \mu \mathrm{g} /$ $\mathrm{ml}$ human plasma fibronectin at $4^{\circ} \mathrm{C}$ overnight and then blocked with $0.1 \%$ heat-inactivated BSA (Calbiochem, San Diego, CA) at $37^{\circ} \mathrm{C}$ for $45 \mathrm{~min}$. MDA-MB-231 and MCF-10F cells were detached at 90\% confluence with 2 $\mathrm{mM}$ EDTA/PBS, washed once in PBS and re-suspended in serum-free DMEM containing 0.1\% BSA. A $300 \mu \mathrm{l}$ cell suspension was added to the upper side of the inserts at a density of $3 \times 10^{4}$ cells/insert before antiATP synthase $\alpha$-subunit primary mAb $(100 \mu \mathrm{g} / \mathrm{ml})$ and negative control mIgG $(100 \mu \mathrm{g} / \mathrm{ml})$ were incubated with the cells for $30 \mathrm{~min}$. DMEM containing 1\% FBS was added to the lower wells. Invasion was allowed to proceed at $37^{\circ} \mathrm{C}$ for 8 and $24 \mathrm{~h}$. Cells that did not migrate through the filters were removed using cotton swabs, and cells that migrated through the inserts were fixed and stained with Trypan Blue. The number of migrated cells per insert was counted under a light microscope at magnification $20 \times$. Experiments were carried out in triplicate and repeated at least three times. Data from several independent experiments were pooled and analyzed using a two-tailed, Student's t test.

\section{$\mathrm{RT}^{2}$ Profiler PCR array}

SABioscience Human Apoptosis PCR Array PAHS-3012 (Qiagen China, Shanghai, China) is an apoptosis pathway-focused gene expression profiling using real-time PCR. The system allows one to identify genes involved in apoptosis and programmed cell death. The array includes the TNF ligands and their receptors; members of the bcl-2 family, BIRC (baculoviral IAP repeat) domain proteins, CARD domain (caspase recruitment domain) proteins, death domain proteins, TRAF (TNF receptor-associated factor) domain proteins and caspases. RNA was isolated using RNA easy Mini kit (Qiagen). The single strand cDNA from $1 \mathrm{mg}$ total RNA was synthesized using $\mathrm{RT}^{2}$ First Strand Kit (SABioscience). Real-time PCR was performed according to the user manual of $\mathrm{RT}^{2}$ Profiler PCR array system (SABioscience) using SYBR Green PCR Master Mix in a Light Cycler 480 system (Roche Diagnostics). Data were analyzed using Excel-based PCR Array Data Analysis Templates (SABioscience). Three samples were analyzed: Control group, MDA-MB-231 cells treated with IgG for 24 hours; Test group 1, MDA-MB-231 cells treated with MAb9E10 $100 \mathrm{mg} / \mathrm{ml}$ for 24 hours; Test group 2, MDA-MB-231 cells treated with MAb9E10 $100 \mathrm{mg} / \mathrm{ml}$ for 48 hours.

\section{Statistical analysis}

The breast tissue array data were transferred to a PC and statistically analyzed using SPSS Version 10 for Windows (SPSS Inc., Chicago, IL). Correlation of the ATP synthase expression between the several different clinic pathological factors was calculated with the nonparametric Spearman correlation coefficient. Results with a $P<0.05$ were deemed statistically significant.

\section{Results}

ATP synthase $\alpha$-subunit is over-expressed in the highly invasive MCF-7-H subline

To establish an breast carcinoma invasion model, MCF7 cells were seeded onto Matrigel-coated trans wells. The cells were allowed to invade into the lower chamber of the trans well, collected, expanded and then re-seeded onto another Matrigel-coated trans well. Cells were harvested after four rounds of selection, resulting in the establishment of a relatively stable, highly invasive subline, MCF-7-H. The invasive ability of this line was about 3.3-fold greater than that of the MCF-7 parent cell line (Figure 1A) in Matrigel invasion tests, but equal to that of the third selection round line, suggesting that the metastatic potential of the subline reached a plateau 
A
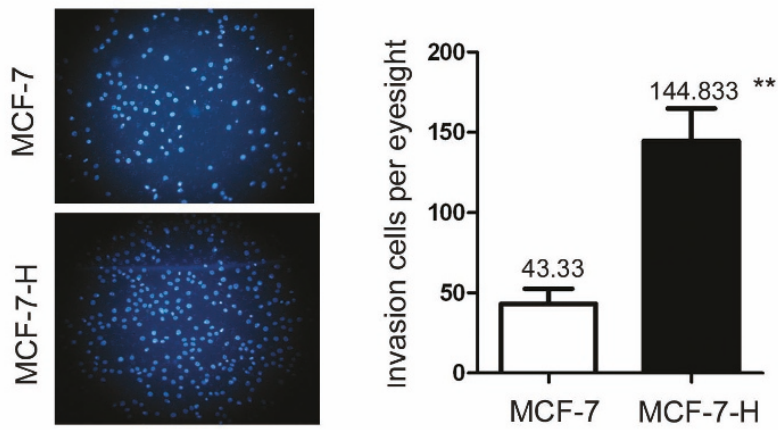

B
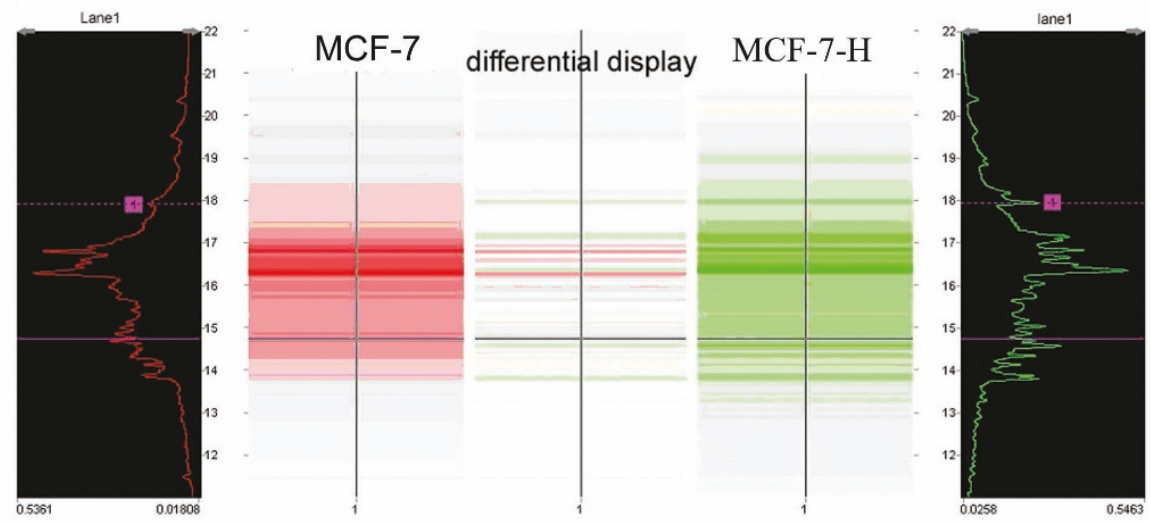

Absorbance Unit (V) Fraction \#

C

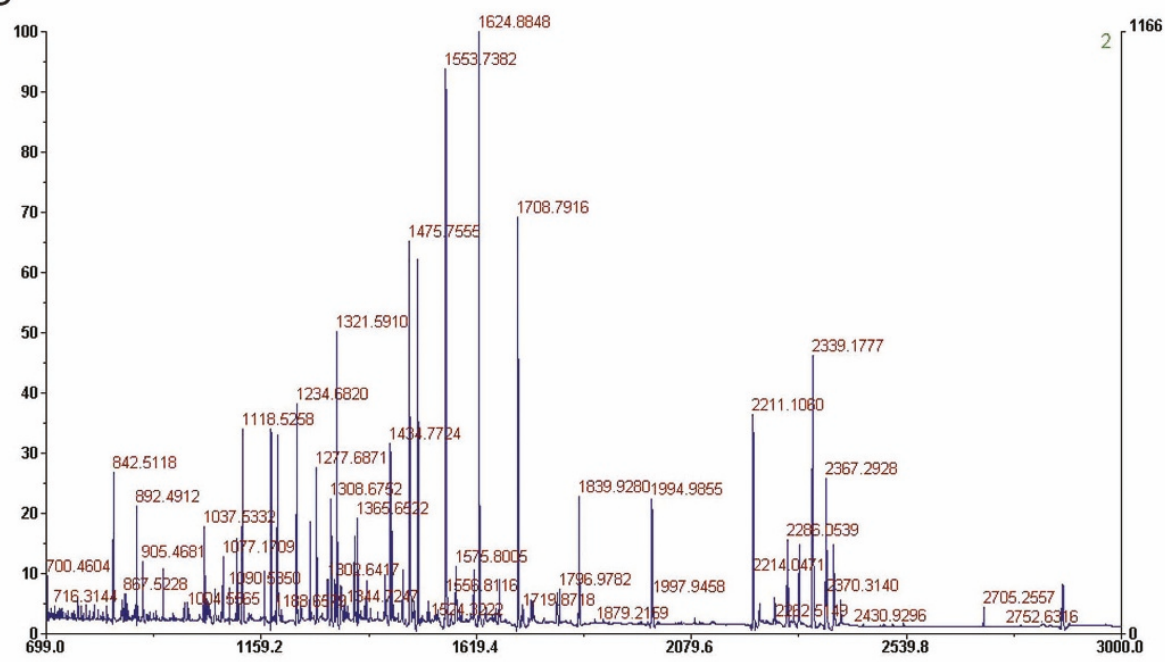

Figure 1 Identification of ATP synthase $\alpha$-subunit as a differentially expressed protein between MCF-7-H and MCF-7 cells by PF 2D and MALDI-TOF-MS. $\boldsymbol{A}$, The sub-line MCF-7-H was selected from MCF-7 cells for high invasive ability using the trans well invasion assay, cells were stained with DAPI and the asterisks ** indicate $\mathrm{P}<0.01$. $\boldsymbol{B}$, The display map of differentially expressed proteins between the MCF-7-H and MCF-7 cell lines. The image was analyzed by ProteoVue and DeltaVue software. ProteoVue allows comparison of multiple or all second dimension runs for one sample in a 2-D map using either gray scale or a color-coded format, where color hue or its intensity is proportional to the relative quantitative UV intensity of each peak. The DeltaVue software quantitatively displays one protein map in shades of red and the other map in shades of green. The difference between the two maps is obtained by point-by-point subtraction or by area difference and displayed as a third map in the middle. The color (red or green) at a particular location in the difference map indicates which protein is more abundant, and the color brightness indicates the quantitative difference. $C$, MALDI-TOF mass spectrum of ATP synthase $\alpha$-subunit after trypsin digestion. MSDigest search using the peptide mass fingerprint data indicated that 10 peptides were matched with peptides from ATP synthase $\alpha$-subunit, giving sequence coverage of $28 \%$ (126/450 aa) of the protein. 
by the fourth round of selection. Thus, by Matrigel invasive subpopulation selection, we were able to establish the highly invasive and metastatic breast cancer cell line MCF-7-H.

\section{2-D liquid chromatography and MALDI-TOF MS analysis} Image analysis of the 2-D map revealed 72 protein peaks with significantly differential expression between MCF$7-\mathrm{H}$ and MCF-7 cells, and 9 of these protein peaks were further identified by tryptic digestion, peptide mass fingerprinting and MS. Five proteins were down-regulated and four proteins up-regulated in MCF-7-H cells, including ATP synthase $\alpha$-subunit. The display map of differentially expressed proteins between the MCF-7-H and MCF-7 cell lines and the MALDI-TOF/MS tryptic peptide mass map of ATP synthase $\alpha$-subunit are shown in Figure $1 \mathrm{~B}$ and $1 \mathrm{C}$, respectively. MS-Digest search using the peptide mass fingerprint data indicated that 10 peptides were matched with peptides from ATP synthase $\alpha$-subunit, giving sequence coverage of $28 \%$ $(126 / 450 \mathrm{aa})$ of the protein. The amino acid sequence of this protein can be accessed in the National Center for Biotechnology Information (NCBI) protein database under NCBI Accession \# 4757810.

\section{IHC and TMA analysis of ATP synthase $\alpha$-subunit}

IHC staining was performed on 214 cases in total. In all 33 normal breast epithelia, a weak or missing ATP synthase $\alpha$-subunit signal was detected at the cell membrane and in the cytoplasm. The overall percentage of atypical hyperplasia breast tissues staining positive for ATP synthase $\alpha$-subunit was $23.1 \%$ (3/13), while that in breast cancer tissues was $94.6 \%$ (159/168) (Table 1). Detection of the ATP synthase $\alpha$-subunit was strong in 98 breast cancer patients $(58.3 \%)$, moderate in 61 patients (36.3\%) and negative in 9 patients $(5.3 \%)$ (Table 2 ). The staining pattern was predominantly at the cellular membrane and cytoplasm (Figure 2E and 2F). The cytoplasmic immunoreactivity was granular and appeared in epithelial cells. Figure 2 shows an example of the tissue array analysis for ATP synthase $\alpha$-subunit in breast cancer samples, atypical breast hyperplasia and normal breast tissue. Expression of the ATP synthase $\alpha$ subunit in breast cancer (Figure 2C and 2D) was

Table 1 ATP synthase expression in normal, atypical breast hyperplasia and breast cancer tissues

\begin{tabular}{ccccc}
\hline & N & \multicolumn{2}{c}{ ATP synthase expression } & P value \\
& & Negative & Positive & \\
\hline Normal & 33 & 26 & $7(21.2 \%)$ & $<0.001$ \\
Hyperplasia & 13 & 10 & $3(23.1 \%)$ & \\
breast cancer & 168 & 9 & $159(94.6 \%)$ & \\
\hline
\end{tabular}

$P$ value of chi-square analysis. significantly higher than in breast atypical hyperplasia and normal breast tissues (Figure 2G, H, I, J and 2K). The analysis showed that the higher ATP synthase $\alpha$ subunit expression was significantly associated with tumor size, histological grade and stage $(P<0.05)$. No statistically significant differences were found among cases with different ages or lymph node invasion $(P>$ 0.05) (Table 2). Analysis of gene expression data sets from a cancer gene microarray meta-analysis public database [27] http://www.oncomine.org revealed that ATP synthase $\alpha$-subunit mRNA expression is markedly higher in carcinoma cell lines than in normal tissues and cell lines (Additional file 1).

Analysis of ATP synthase $\alpha$-subunit surface expression on breast cancer cells by immunofluorescence microscopy and flow cytometry

Immunofluorescence microscopy analysis using a specific antibody confirmed the surface localization of the ATP synthase $\alpha$-subunit on non-permeabilized MDAMB-231 cells (Figure 3A). Control experiments were performed with isotype mouse IgG (Figure $3 \mathrm{C}, \mathrm{F}$ ) and permeabilized cells in the presence of the anti- $\alpha$-subunit ATP synthase antibody (Figure 3B, E). While the permeabilized normal breast cell line MCF-10F (Figure 3E) also reacted with the anti-ATP synthase $\alpha$-subunit antibody, no specific reactivity was observed with non-permeabilized MCF-10F cells (Figure 3D). Surface expression of ATP synthase on MDA-MB-231 and MCF-10F cells were further assessed by flow cytometry. The results showed a significantly higher proportion of MDA-MB-231 cells (54.1 $\pm 12.4 \%)$ with ecto-expression of the ATP synthase $\alpha$-subunit compared with the IgG isotype control group $(2.4 \pm 1.7 \%)(P<0.01$, Figure $4 \mathrm{~A}$, B). No ecto-expression of the ATP synthase $\alpha$-subunit was detected in MCF-10F cells $(4.5 \pm 3.4 \%)$ when compared with its control group $(5.4 \pm 2.5 \%)(P>0.05$, Figure $4 \mathrm{~A}, \mathrm{~B})$. We also detected the ecto-expression of ATP synthase $\alpha$-subunit in other three breast cell lines, and the ecto-expression is from $5.83 \%$ to $52.72 \%$ in these cell lines (Figure 4C)

\section{Anti-proliferative effect of anti-ATP synthase $\alpha$-subunit antibody on breast cancer cells}

To gain insight into the function of ATP synthase in breast cancer and test whether ATP synthase represents a potential therapeutic target, we used MAb9E10, an anti-ATP synthase $\alpha$-subunit mAb produced as previously described [26]. After blockade of surface ATPase with this $\mathrm{mAb}$ on human breast adenocarcinoma MDAMB-231 cells, an ATP determination kit and CellTiter96 AQueous Assay (MTS) assay were used to detect the effect of the antibody on extracellular ATP modification and cell proliferation. Results showed that MAb9E10 
Table 2 Clinic pathological data and ATP synthase $\alpha$-subunit expression in 168 breast cancers

\begin{tabular}{|c|c|c|c|c|c|}
\hline & \multicolumn{3}{|c|}{$\alpha$-ATP synthase expression } & \multirow[t]{2}{*}{ Total } & \multirow[t]{2}{*}{$P$ value } \\
\hline & Negative & Moderate & Strong & & \\
\hline \multicolumn{6}{|l|}{ Age } \\
\hline$<50$ & $5(7.0 \%)$ & $30(42.3 \%)$ & $36(50.7 \%)$ & $71(100 \%)$ & Not significant \\
\hline$\geq 50$ & $4(4.1 \%)$ & $31(32.0 \%)$ & $62(63.9 \%)$ & $97(100 \%)$ & \\
\hline \multicolumn{6}{|l|}{ Size } \\
\hline$<2 \mathrm{~cm}$ & $2(13.3 \%)$ & $10(66.7 \%)$ & $3(20.0 \%)$ & $15(100 \%)$ & $P<0.05$ \\
\hline$\geq 2 \mathrm{~cm}$ & $2(3.6 \%)$ & $24(42.8 \%)$ & $30(53.6 \%)$ & $56(100 \%)$ & \\
\hline \multicolumn{6}{|l|}{ Histological grade } \\
\hline Well differentiated & $3(12.5 \%)$ & $11(45.8 \%)$ & $10(41.7 \%)$ & $24(100 \%)$ & $P<0.05$ \\
\hline Moderately differentiated & $6(5.3 \%)$ & $43(37.7 \%)$ & $65(57.0 \%)$ & $114(100 \%)$ & \\
\hline Poorly differentiated & $0(0.0 \%)$ & $3(15.0 \%)$ & 17 (85.0\%) & $20(100 \%)$ & \\
\hline \multicolumn{6}{|l|}{ TNM Stage } \\
\hline I & $2(22.2 \%)$ & $4(44.5 \%)$ & $3(33.3 \%)$ & $9(100 \%)$ & $P<0.05$ \\
\hline$\|$ & $2(4.6 \%)$ & $24(54.5 \%)$ & $18(40.9 \%)$ & $44(100 \%)$ & \\
\hline III & $0(0.0 \%)$ & $3(23.1 \%)$ & $10(76.9 \%)$ & $13(100 \%)$ & \\
\hline \multicolumn{6}{|l|}{ Lymph node invasion } \\
\hline Positive & $3(5.9 \%)$ & $18(35.3 \%)$ & $30(58.8 \%)$ & $51(100 \%)$ & Not significant \\
\hline Negative & $2(4.8 \%)$ & $11(26.2 \%)$ & $29(69.0 \%)$ & $42(100 \%)$ & \\
\hline
\end{tabular}

$P$ value of chi-square analysis.

inhibited the MDA-MB-231 cell proliferation in a concentration-dependent manner. The growth of MDAMB-231 cells treated with MAb9E10 was significantly suppressed compared with that of cells treated with IgG control. The proliferation of cells (OD450 $=0.87 \pm 0.65)$ treated with MAb9E10 in the high dose group $(100 \mu \mathrm{g} /$ $\mathrm{ml}$ ) was significantly lower than that of the mIgG control group $(\mathrm{OD} 450=1.98 \pm 1.13)$ (Figure 5A). There was no inhibition of proliferation when MCF-10F cells were treated with high dose $(100 \mu \mathrm{g} / \mathrm{ml})$ MAb9E10 $(\mathrm{OD} 450=2.19 \pm 0.65)$, which was nearly equal to that of the control group (OD450 = $2.47 \pm 1.23$ ) (Figure 5A).

\section{Inhibition of MDA-MB-231 migration and invasion by anti-ATP synthase $\alpha$-subunit antibody}

To investigate the effect of ATP synthase expression on cell motility and whether ATP synthase is involved in the progression and metastasis of breast cancer, the MDA-MB-231 and MCF-10F metastatic breast cancer cell lines were then tested for their directional motility on fibronectin and for their invasion ablity in a chemohaptotactic invasion assay. MDA-MB-231 cells treated with MAb9E10 $(100 \mu \mathrm{g} / \mathrm{ml})$ showed lower migration ability (66.2\% migration inhibition) compared with IgG control treatment $(P<0.01$; Figure $5 \mathrm{~B})$. There was no significant inhibition of migration (7.8\%) when MCF$10 \mathrm{~F}$ cells were treated with MAb9E10 at the same dose $(P>0.05$; Figure 5B). In trans well assays, MDA-MB231 cells treated with MAb9E10 $(100 \mu \mathrm{g} / \mathrm{ml})$ also showed a lower invasion ability (61.3\% invasion inhibition) compared with IgG control treatment $(P<0.01$; Figure $5 \mathrm{C}$ ). There was also no significant inhibition of invasiveness of MCF-10F cells treated with MAb9E10 at the same dose $(3.4 \%)$ vs. the mIgG control group $(P>$ 0.05; Figure 5C).

\section{Anti-ATP synthase $\alpha$-subunit antibody regulated apoptosis pathway of MDA-MB-231 cells}

In order to identify apoptosis and/or programmed cell death molecules implicated into the treatment with antiATP synthase $\alpha$-subunit antibody, we used the SABioscience Human Apoptosis PCR Array PAHS-3012. We analyzed the expression of 370 key genes involved in apoptosis, or programmed cell death with this PCR Array (Figure 6A, B). This array includes the TNF ligands and their receptors; members of the bcl-2 family, BIRC (baculoviral IAP repeat) domain proteins, CARD domain (caspase recruitment domain) proteins, death domain proteins, TRAF (TNF receptor-associated factor) domain proteins and caspases. Using this real-time PCR, we can easily and reliably analyze the expression of a focused panel of genes related to apoptosis with this array. Comparison of PCR results between Test group and control group showed that 23 genes were significantly up-regulated and 18 genes were significantly down-regulated both in test group 1 and 2 (fold changes Table 3 and Table 4). The raw data of PCR array was attached in additional file 2 . Results showed that treated 


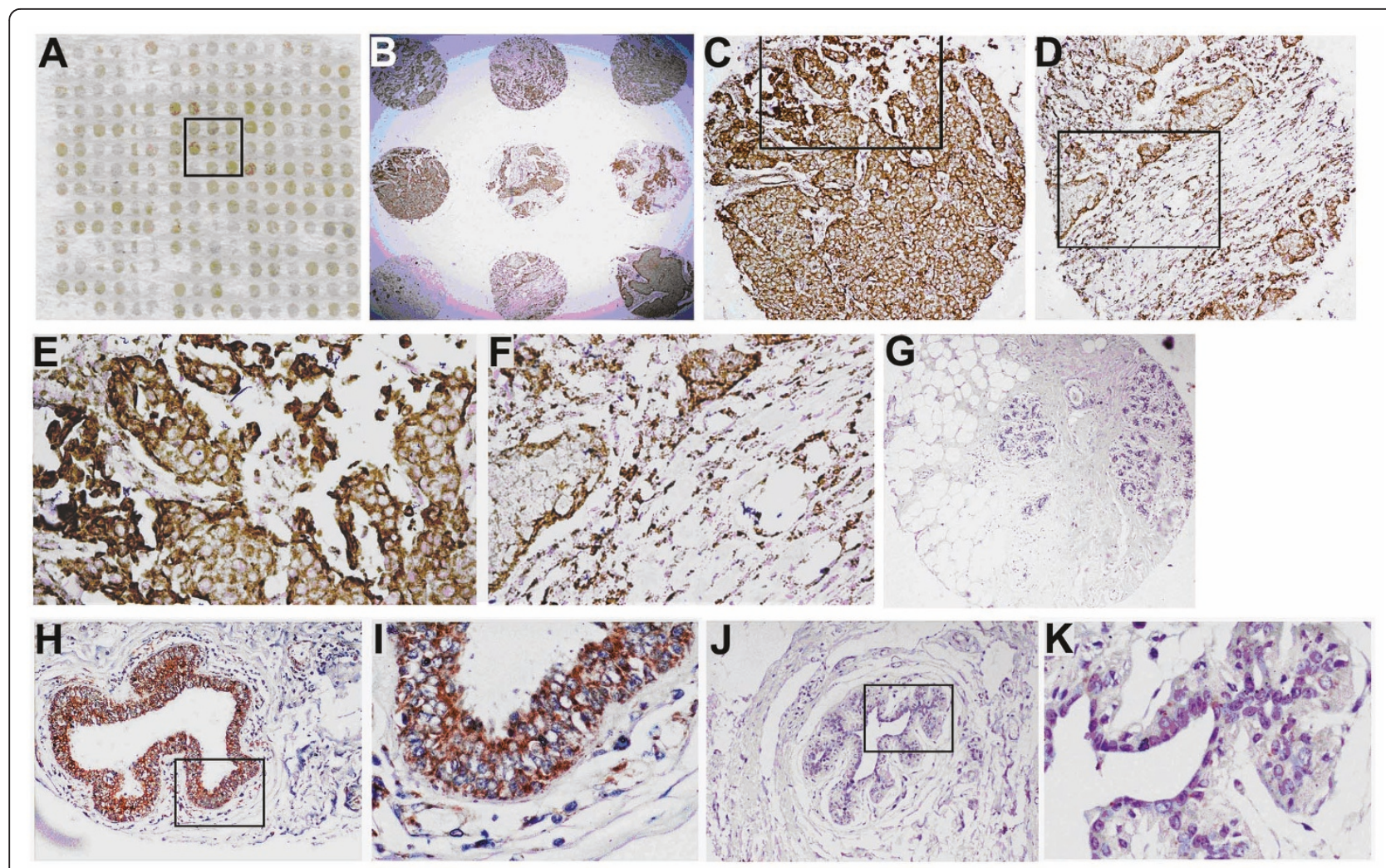

Figure 2 IHC analysis of ATP synthase $\alpha$-subunit expression in breast cancer tissue, atypical breast hyperplasia and normal breast tissue. The breast cancer tissue microarrays were probed with the anti-ATP synthase $\alpha$-subunit mAb (brown), and hematoxylin was used for counterstaining (blue). $\boldsymbol{A}$, A representative arrangement of "spots" on the breast cancer tissue microarray slide. $\boldsymbol{B}$, Low-power magnification shows strong and moderate immunoreactivity samples on the microarray slide (40x). $\mathbf{C}$ and $\mathbf{D}$, Examples of a strong and a moderate immunostaining, respectively, of ATP synthase $\alpha$-subunit in epithelial cells of breast infiltrating duct carcinoma samples at increased magnification (200x). $\boldsymbol{E}$ and $\mathbf{F}, \mathrm{A}$ high-power view suggests immunoreactivity of the ATP synthase $\alpha$-subunit antibody in the cellular membrane and granular cytoplasmic distribution (400X). $\boldsymbol{G}$, Absent staining in normal breast tissue. Original magnification (200x). $\boldsymbol{H}, \boldsymbol{I}, \boldsymbol{J}$ and $\boldsymbol{K}$, Atypical breast hyperplasia exhibiting a less intense $(H$ and $I)$ or absent immunostaining $(J$ and $K)$ at low-power $(H$ and $J, 200 x)$ and high-power $(I$ and $K$, 400x) magnifications.

with Anti-ATP synthase $\alpha$-subunit antibody, a lot of apoptosis induced genes were up-regulated: FOXO1 (30.64), CASP9 (17.37) and CASP7 (4.43). A lot of antiapoptotic genes were down-regulated at the same time: CARD9 (-34.63), CCL2 (-16.47) and BIRC3 (-9.66). These data could partially explain the function of AntiATP synthase $\alpha$-subunit antibody.

\section{Discussion}

In this study we combined several advanced techniques, such as proteomic analysis using the Proteome Lab PF 2D fractionation system, MALDI-TOF/MS and tissue microarray, with functional analysis to identify novel biomarkers for improved prediction of progression, metastasis and response to therapy for breast cancer. The work was also performed in an attempt to better understand molecular mechanisms involved in breast cancer carcinogenesis and metastasis. Our studies revealed one highly over-expressed protein, the $\alpha$ - subunit of ATP synthase, in breast cancer. This observation was validated, refined and extended through a series of IHC on tissue microarray, immunofluorescence and functional analyses. The over-expression of ATP synthase $\alpha$-subunit was detected by IHC in several different human tumor samples, including breast cancer, hepatocellular carcinoma, colon cancer and prostate cancer (data not shown). Since ATP synthase $\alpha$-subunit was highly over-expressed in $94.6 \%$ of breast cancer samples tested while being undetectable in normal breast tissues, this study was focused on the expression, functional implication and potential involvement of ATP synthase in the progression and metastasis of breast cancer. Levels of ATP synthase $\alpha$-subunit expression were strongly correlated with large tumor size, poor tumor differentiation and advanced stages of tumor. High expression of ATP synthase in breast cancer compared to normal breast tissue and hyperplasia indicates that it can serve as a biomarker in screening, 


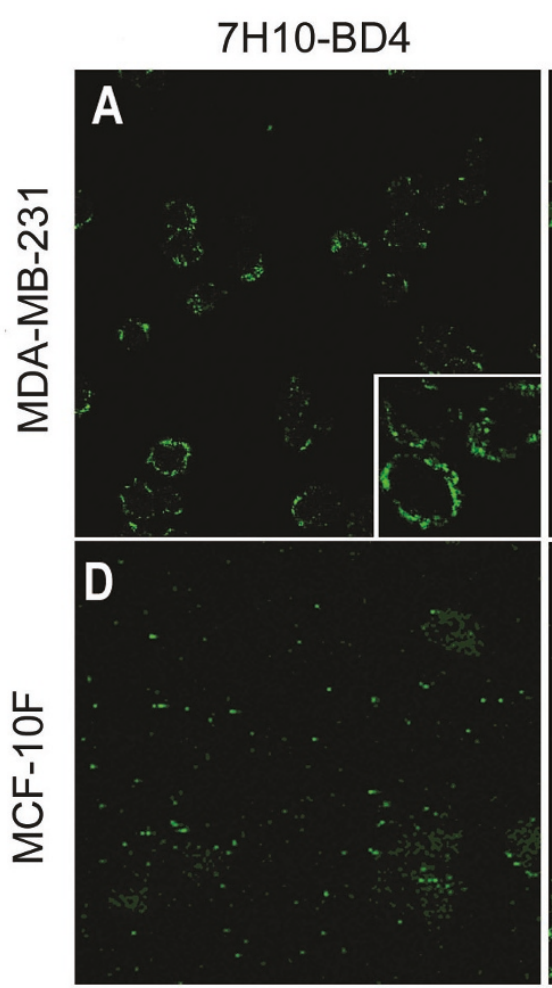

Nonpermeabilized
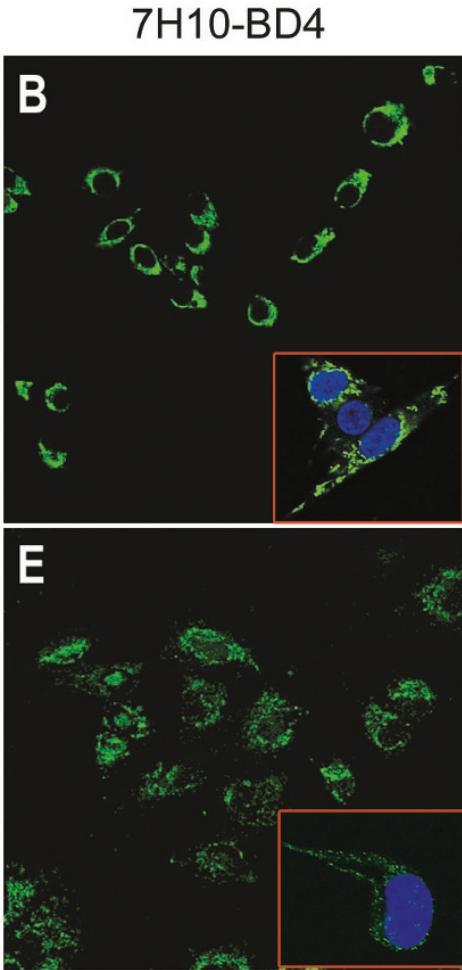

Permeabilized

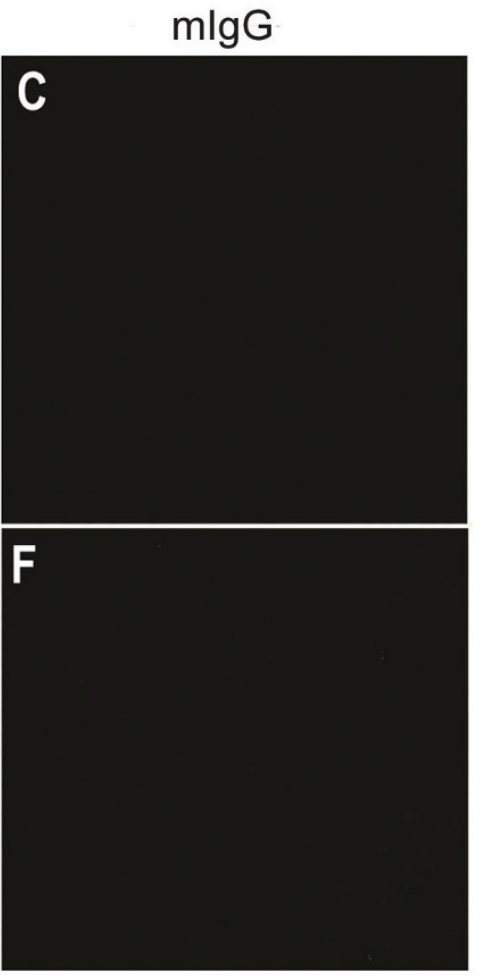

Permeabilized

Figure 3 Immunofluorescence localization of the ATP synthase $\alpha$-subunit on the surface of breast cancer cells by confocal microscopy. Cells were stained with an $\boldsymbol{\alpha}$-ATP synthase antibody, followed by secondary antibody, as detailed in Materials and Methods. $\boldsymbol{A}$ and $\boldsymbol{D}$, Nonpermeabilized MDA-MB-231 and MCF-10F immunostained with a murine mAb specific for the ATP synthase $\boldsymbol{\alpha}$-subunit(600x). $\boldsymbol{B}$ and $\boldsymbol{E}$, Image obtained from MDA-MB-231 and MCF-10F cells permeabilized with ethanol (100\%). $\boldsymbol{C}$ and $\mathbf{F}$, Control experiments for antibody specificity using isotypic purified mouse lgG in cells(600x).

diagnosis and prediction of breast cancer progression. ATP synthase expression may also be useful when used in combination with more traditional pathologic indicators such as tumor size, TNM stage and tumor grade to ascertain the prognosis of breast cancer patients.

Prior studies using DNA arrays relied on the expression of gene transcript in cancers, with little focus on the detection of the protein [28]. With the recent development of similar technologies at the DNA and protein levels and several studies demonstrating the clinical potential of the proteomic approach, there is no reason to limit profiling to RNA. Proteomic analysis has the potential to complement and further enlarge the wealth of information generated by genomics for several reasons. Levels of mRNA levels do not necessarily correlate with corresponding protein abundance, as additional complexity is conferred by protein post-translational modifications, including phosphorylation, acetylation and glycosylation, or protein cleavage. These modifications are not detectable at the mRNA level but play significant roles in protein stability, localization, interactions and functions. Finally, proteins represent more accessible and relevant therapeutic targets than nucleic acids. Thus, we surveyed primary breast cancers for expression of ATP synthase by immunostaining with the mouse anti- $\alpha$-subunit ATP synthase antibody and found a high frequency of immunoreactivity.

During energy generation in the mitochondria, the ATP synthase is driven by a gradient of protons across a membrane, produced by the organelle's oxygen-burning metabolism [13]. However, in a low oxygen or acidosis microenvironment, where mitochondria ATP synthase levels are very low, the cell surface ATP synthase of tumor cells may manufacture the ATP using the gradient from the inside of cells compared to the outside, which could result from the lack of oxygen [29-31]. When mitochondria are in low oxygen conditions or matrix $\mathrm{pH}$ decreases, the proton gradient favorable for ATP synthesis declines [32]. Therefore, it may be more feasible for the cell in such an environment to produce ATP on its surface. For example, ATP synthase shows greater activity under conditions of acidosis, a hallmark of the tumor microenvironment [33]. Cell-surface-generated ATP may be transported into the cell to provide a 


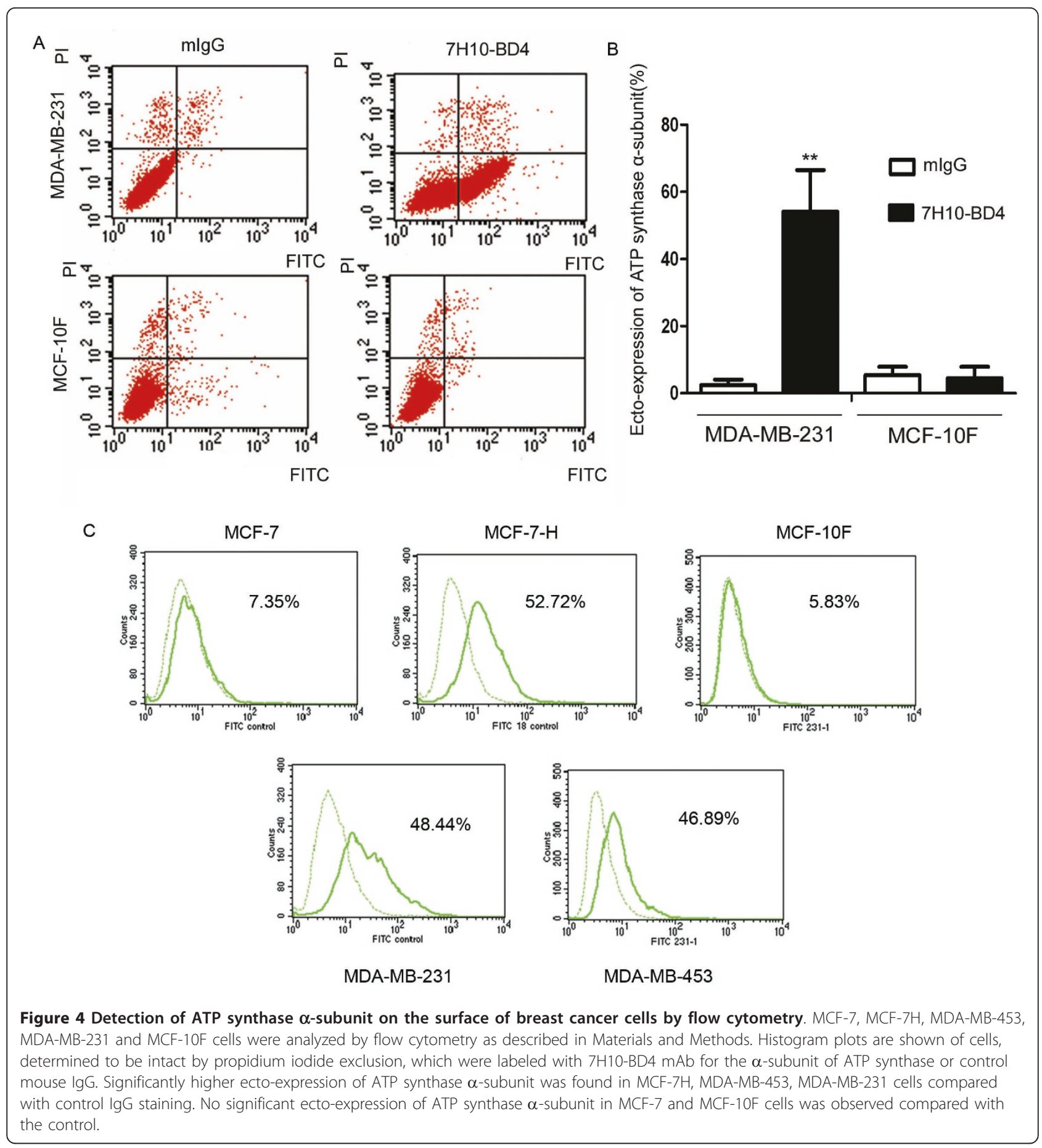

source of energy in the tumor microenvironment where intracellular levels are very low. It is hypothesized that certain lethal tumor phenotypes, such as invasion and metastasis, arise not only from genetic alterations within the tumor but from tumor microenvironmental stimuli, such as acidosis. Endothelial and tumor cells could also have a plentiful supply of ADP for conversion to ATP to provide cancer cells with an extra energy source for survival since red blood cells release high levels of ADP in low-oxygen conditions.

Cellular invasiveness is an enhanced or aberrant cell movement and a major characteristic of poorly differentiated cancers [34]. In metastatic cancers, cells usually acquire the ability to invade surrounding tissues and then metastasize to secondary lesions. Therefore, the aberrant motile feature of cancer cells is responsible for 
A

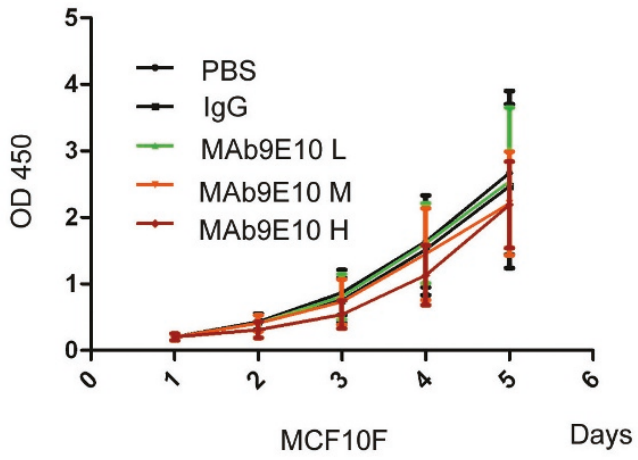

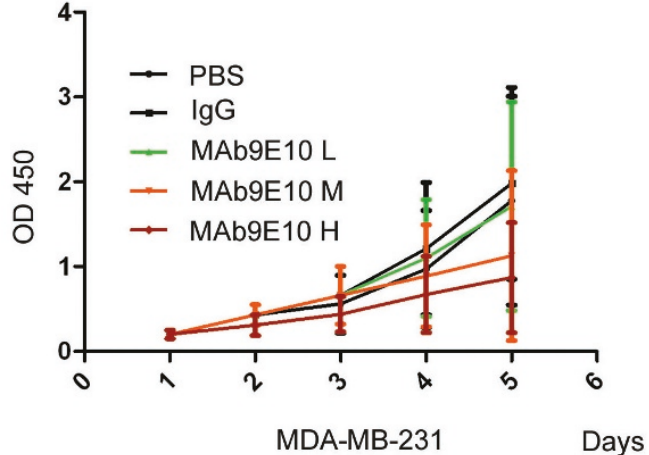

MDA-MB-231
B

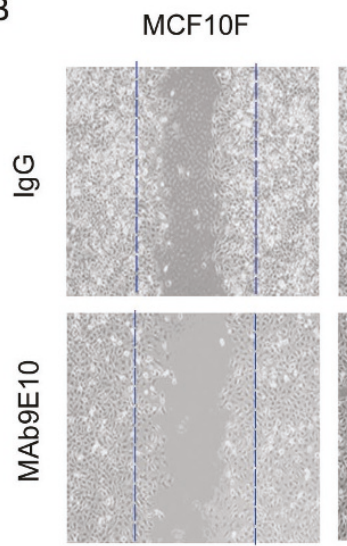

C
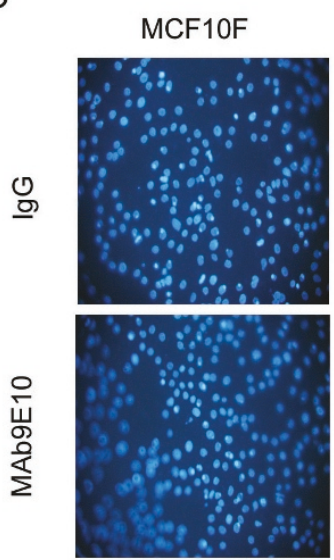

MDA-MB-231
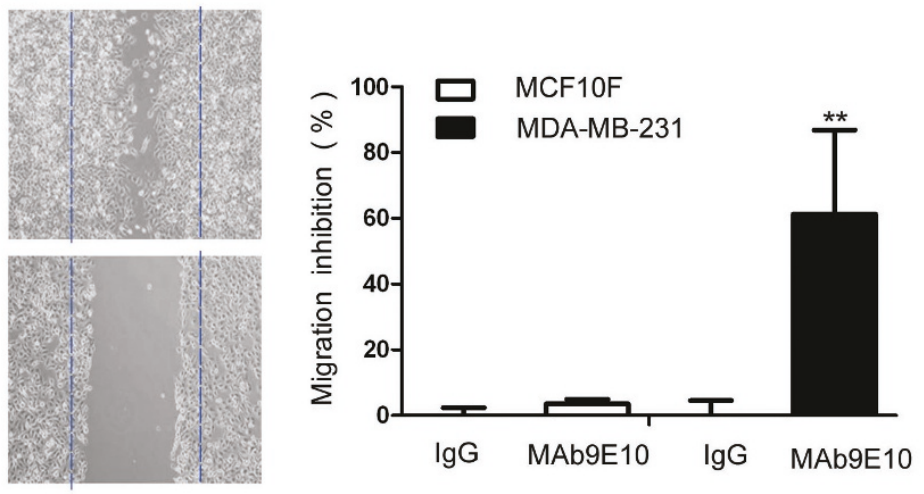

MDA-MB-231
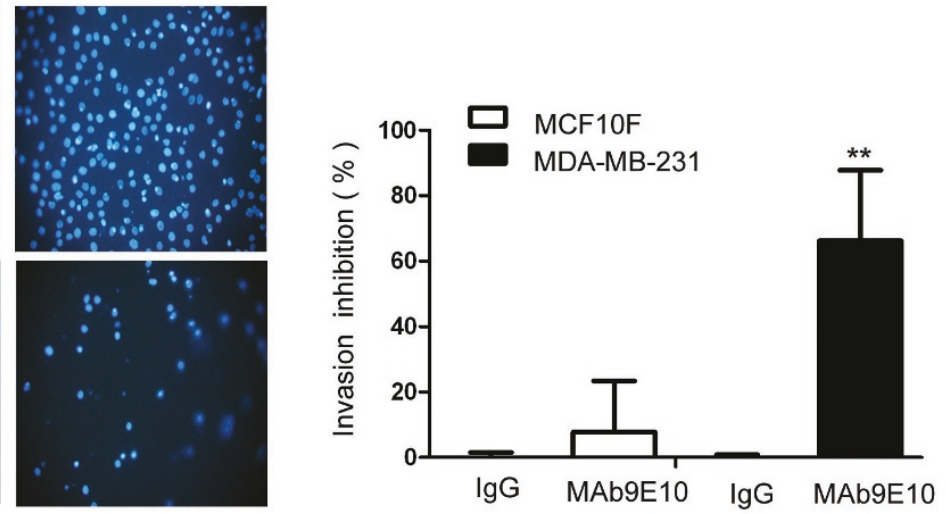

Figure 5 Inhibition of breast cancer cell proliferation, migration and invasion by a functional anti-ATP synthase $\alpha$ - subunit antibody. $A$ , MDA-MB-231 and MCF-10F were plated at a density of 5,000 cells/well in serum-free media for overnight fasting. The $\alpha$-subunit of ATP synthase was added at concentrations of $10 \mu \mathrm{g} / \mathrm{ml}$ (low dose), $50 \mu \mathrm{g} / \mathrm{ml}$ (medium dose) or $100 \mu \mathrm{g} / \mathrm{ml}$ (high dose). CCK-8 solution was added after $24 \mathrm{~h}$, and the absorbance used to calculate percent proliferation was measured on a Thermo max plate reader at a wavelength of $490 \mathrm{~nm}$. Growth of MDA-MB-231 cells treated with high dose MAb9E10 was significantly suppressed compared with IgG control treatment. MCF-10F cell proliferation was not inhibited by MAb9E10 treatment. B, Migration of MDA-MB-231 and MCF-10F cells were measured using wound-healing assays. MDA-MB-231 cells treated with MAb9E10 $100 \mu \mathrm{g} / \mathrm{ml}$ showed lower migration ability comparing with mlgG control; ** $P<0.01$. No significant inhibition of migration was observed when MCF-10F cells were treated with MAb9E10. $C$, Invasion of MDA-MB-231 cells was measured using transwell inserts coated with fibronectin $(10 \mu \mathrm{g} / \mathrm{ml})$. After treatment with anti-ATP synthase $\alpha$-subunit antibody or control mlgG, cells that migrated through the filters onto the lower surface were fixed, stained and photographed (200X). In each individual experiment, the invaded cells were counted from at least three randomly selected fields. Results were averaged from at least three individual experiments. MDAMB-231 cells treated with MAb9E10 $100 \mu \mathrm{g} / \mathrm{ml}$ also showed lower invasion ability comparing with mlgG control (Figure 5C). Almost no inhibition of invasion when MCF-10F cells treated with MAb9E10. The bar graph displays means \pm S.D; ** $P<0.01$. 


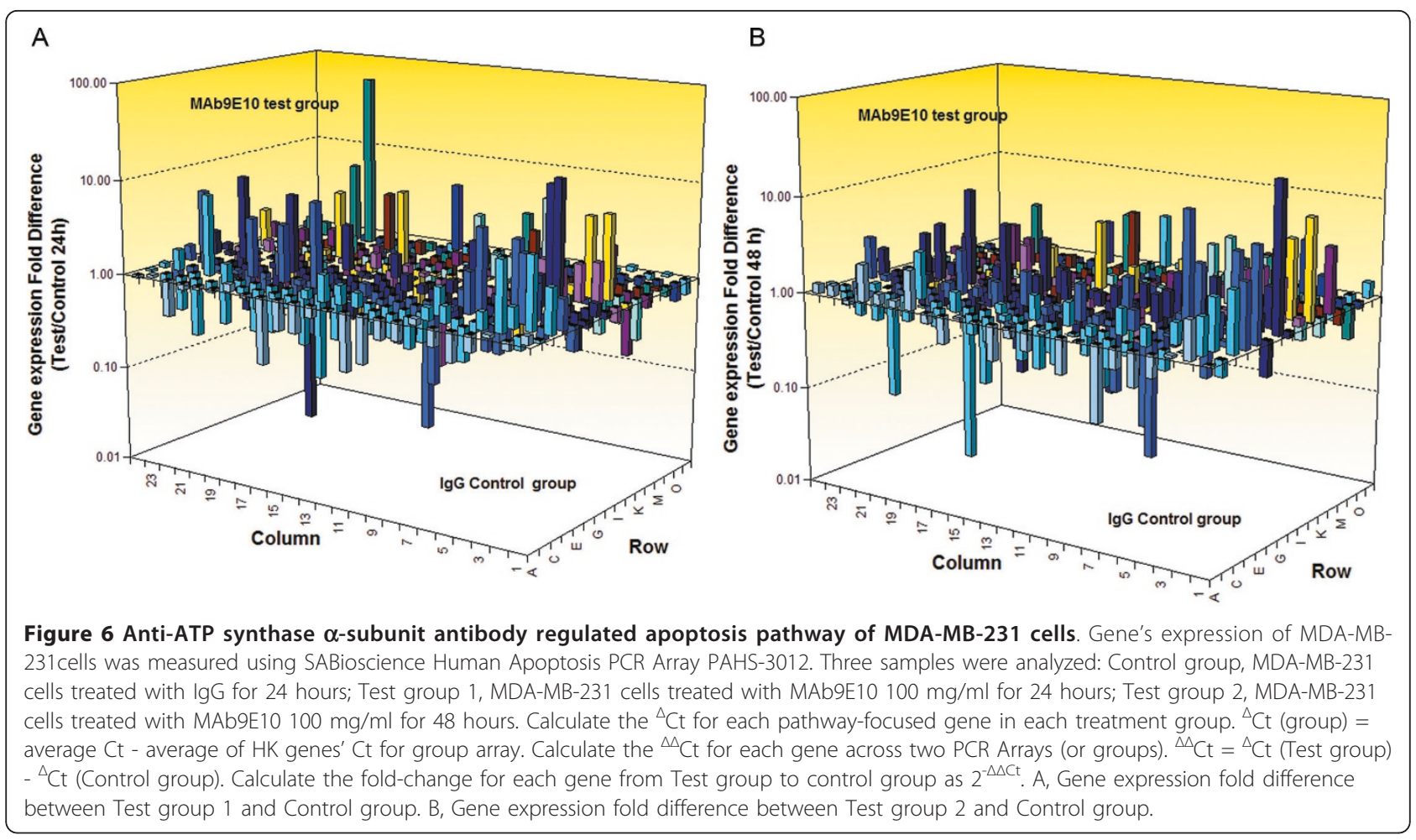

Table 3 Up regulated genes of MDA-MB-231 cells treated with MAb9E10 antibody 24 and 48 hours (Fold change)

\begin{tabular}{|c|c|c|c|c|c|}
\hline & Symbol & UniGene & Description & $24 \mathrm{~h}$ group & $48 \mathrm{~h}$ group \\
\hline 1 & FOXO1 & Hs.370666 & Forkhead box $\mathrm{O} 1$ & 17.95 & 30.64 \\
\hline 2 & CASP9 & Hs.329502 & Caspase 9, apoptosis-related cysteine peptidase & 2.67 & 17.37 \\
\hline 3 & NDUFS3 & Hs.502528 & NADH dehydrogenase (ubiquinone) Fe-S protein 3, $30 \mathrm{kDa}$ (NADH-coenzyme Q reductase) & 7.48 & 10.73 \\
\hline 4 & HSPA1B & Hs.274402 & Heat shock $70 \mathrm{kDa}$ protein 1B & 7.68 & 9.62 \\
\hline 5 & COL4A3 & Hs.570065 & Collagen, type IV, alpha 3 (Goodpasture antigen) & 2.23 & 8.86 \\
\hline 6 & NFKB1 & Hs.654408 & Nuclear factor of kappa light polypeptide gene enhancer in B-cells 1 & 6.71 & 6.3 \\
\hline 7 & $\mathrm{~F} 2 \mathrm{R}$ & Hs.482562 & Coagulation factor II (thrombin) receptor & 6.59 & 5.38 \\
\hline 8 & CRYAB & Hs.408767 & Crystallin, alpha B & 6.62 & 4.97 \\
\hline 9 & SOCS2 & Hs.485572 & Suppressor of cytokine signaling 2 & 4.09 & 4.89 \\
\hline 10 & NOD2 & Hs.592072 & Nucleotide-binding oligomerization domain containing 2 & 6.46 & 4.88 \\
\hline 11 & PIK3R2 & Hs.371344 & Phosphoinositide-3-kinase, regulatory subunit 2 (beta) & 1.72 & 4.75 \\
\hline 12 & PRKCE & Hs.580351 & Protein kinase $C$, epsilon & 2.83 & 4.66 \\
\hline 13 & CASP7 & Hs.9216 & Caspase 7, apoptosis-related cysteine peptidase & 4.85 & 4.43 \\
\hline 14 & $\mathrm{TBX} 3$ & Hs.714737 & T-box 3 & 3.6 & 4.24 \\
\hline 15 & BIRC8 & Hs.348263 & Baculoviral IAP repeat containing 8 & 2.88 & 4.08 \\
\hline 16 & PIM2 & Hs.496096 & Pim-2 oncogene & 4.23 & 3.79 \\
\hline 17 & HSPB1 & Hs.520973 & Heat shock 27 kDa protein 1 & 1.75 & 3.76 \\
\hline 18 & IL31RA & Hs.55378 & Interleukin 31 receptor A & 3.46 & 3.46 \\
\hline 19 & MADD & Hs.82548 & MAP-kinase activating death domain & 2.06 & 3.43 \\
\hline 20 & PEA15 & Hs.517216 & Phosphoprotein enriched in astrocytes 15 & 7.8 & 3.38 \\
\hline 21 & BNIP1 & Hs.145726 & BCL2/adenovirus E1B $19 \mathrm{kDa}$ interacting protein 1 & 5.48 & 3.28 \\
\hline 22 & CASP14 & Hs.466057 & Caspase 14 , apoptosis-related cysteine peptidase & 7.09 & 3.09 \\
\hline 23 & MAL & Hs.80395 & Mal, T-cell differentiation protein & 2.42 & 3.04 \\
\hline
\end{tabular}


Table 4 Down regulated genes of MDA-MB-231 cells treated with MAb9E10 antibody 24 and 48 hours (Fold change)

\begin{tabular}{clllll}
\hline & Symbol & UniGene & Description & 24 h group & 48 h group \\
\hline 1 & CARD9 & Hs.694071 & Caspase recruitment domain family, member 9 & -3.18 & -34.63 \\
2 & CCL2 & Hs.303649 & Chemokine (C-C motif) ligand 2 & -5.91 & -16.47 \\
3 & CUL3 & Hs.372286 & Cullin 3 & -20.23 & -10.06 \\
4 & BIRC3 & Hs.127799 & Baculoviral IAP repeat containing 3 & -3.96 & -9.66 \\
5 & IL18 & Hs.83077 & Interleukin 18 (interferon-gamma-inducing factor) & -2.05 & -8.89 \\
6 & TP63 & Hs.137569 & Tumor protein p63 & -3.43 & -8.6 \\
7 & SPP1 & Hs.313 & Secreted phosphoprotein 1 & -2.88 & -7.61 \\
8 & TNFRSF21 & Hs.443577 & Tumor necrosis factor receptor superfamily, member 21 & -3 & -6.72 \\
9 & F2 & Hs.655207 & Coagulation factor II (thrombin) & -35.19 & -5.9 \\
10 & AIFM3 & Hs.163543 & Apoptosis-inducing factor, mitochondrion-associated, 3 & -1.56 & -5.79 \\
11 & CARD8 & Hs.446146 & Caspase recruitment domain family, member 8 & -3.07 & -5.52 \\
12 & PMAIP1 & Hs.96 & Phorbol-12-myristate-13-acetate-induced protein 1 & -4.52 & -4.7 \\
13 & CD27 & Hs.355307 & CD27 molecule & -2.63 & -4.34 \\
14 & HMGB1 & Hs.593339 & High mobility group box 1 & -1.74 & -4 \\
15 & INHA & Hs.407506 & Inhibin, alpha & -5.02 & -3.75 \\
16 & TP53I3 & Hs.50649 & Tumor protein p53 inducible protein 3 & -1.89 & -3.74 \\
17 & BRCA1 & Hs.194143 & Breast cancer 1, early onset & -1.99 & -3.49 \\
18 & MYBL2 & Hs.179718 & V-myb myeloblastosis viral oncogene homolog (avian)-like 2 & -2.42 & -3.32 \\
\hline
\end{tabular}

the initial phase of cancer metastasis, and cell motility or invasiveness is one of the multiple steps that can be inhibited by a cancer metastasis suppressor. ATP synthase may also play critical roles in tumor cell metastases. It was previously identified as the binding target of angiostatin, a potent antagonist of angiogenesis and the growth of tumor cell metastases $[16,35,36]$. F1-F0-ATP synthase constitutes the major (endothelial cells) EC-binding site for angiostatin, which is active in ATP synthesis and inhibits the endothelial cells proliferation by blocking conformational changes of the enzyme complex required for ATP synthesis or hydrolysis. ATP synthase activities of the enzyme are inhibited by angiostatin as well as by antibodies directed against the $\alpha$ - and $\beta$-subunits of ATP synthase in cell-based and biochemical assays. These experimental results suggest that the inhibitors of ATP synthase activity, such as antibodies against ATP synthase, function as antagonists of angiogenesis. Recent studies also suggested that the polyclonal or monoclonal antibodies against the $\beta$-catalytic subunit of F1F0 ATPase could efficiently inhibit the activities of ecto-F1F0 ATPase. Wang et al. [37] demonstrated inhibition of tumor growth in a hepatoma xenograft mouse model using a monoclonal antibody (mAb6F2C4) against the catalytic $\beta$ subunit of ATP synthase. In accordance with findings of Chi et al [38]. and Zhang et al [26] treating MDA-MB-231 cells and HUVECs with other monoclonal antibodies against the $\beta$ subunit of ATP synthase the authors show that mAb6F2C4 inhibits extracellular ATP synthesis to a greater degree at low $\mathrm{pH}(6.7)$ than at normal $\mathrm{pH}(7.4)$.
In order to identify apoptosis and/or programmed cell death molecules implicated into the treatment with antiATP synthase $\alpha$-subunit antibody, we analyzed the expression of 370 key genes involved in apoptosis, or programmed cell death with this PCR Array. PCR Arrays are the most reliable tools for analyzing the expression of a focused panel of genes. High-quality primer design and master mix formulation enable the PCR Array to amplify 384 different gene-specific products simultaneously under uniform cycling conditions. A lot of new genes were identified and these genes may relate with the function of Anti-ATP synthase $\alpha$-subunit antibody.

In the present study, two breast tissue cell lines, MDA-MB-231, the highly invasive breast cancer cell line with a relatively higher level of cell surface ATP synthase $\alpha$-subunit, and MCF10F, an immortalized (non-tumor derived) human breast epithelial cell line with no detectable level of cell surface ATP synthase, were selected to study the role of ATP synthase in cancer cell proliferation and migration. The anti-ATP synthase $\alpha$-subunit antibody exerted a significant inhibitory effect on the proliferation and migration of the breast cancer cells. To our knowledge, our study showed for the first time that antibody mediated blockade of the ATP synthase $\alpha$-subunit antibody can inhibit breast cancer cells and attenuate the directional cell migration of cancer cells in vitro. Although ATP synthase may also play critical roles in tumor cell metastases as the binding target of angiostatin in endothelial cells, a potent antagonist of angiogenesis and the growth of tumor cell metastases, our results showed that an anti-ATP 
synthase $\alpha$-subunit antibody directly inhibited the tumor cell migration. Thus, decreased cell motility and migration likely play a major role in ATP synthase mediated cancer metastasis. The suppression of cell migration by the anti-ATP synthase $\alpha$-subunit antibody was not limited to a specific ECM interaction.

\section{Conclusions}

In summary, our results demonstrated that overexpression of ATP synthase $\alpha$-subunit may be involved in the progression and metastasis of breast cancer, and it may represent a potential biomarker for diagnosis and a promising therapeutic target for anti-tumor and anti-metastasis therapy. The development of antibodies to ATP synthase in place of angiostatin mimetics may be advantageous due to increased specificity and affinity. An antibody against ATP synthase may ultimately prove useful, either alone or in combination with other treatments, to improve the effectiveness of breast cancer therapy.

\section{Abbreviations used}

2-D: two-dimensional; MALDI-TOF/MS: matrix-assisted laser desorption/timeof-flight mass spectrometry; $I \mathrm{HC}$ : immunohistochemistry; ECM: extracellular matrix; FN: fibronectin; LN: laminin; pl: isoelectric point; pTNM: Pathological Tumor-Node-Metastasis; TMA: tissue microarray.

\section{Acknowledgements}

We thank Professor Zhi-hua Yang (Cancer Institute/Cancer Hospital, Chinese Academy of Medical Sciences and Peking Union Medical College, Beijing, China) for kindly help.

This work was supported by grants from the National Key Basic Research Program No. 2010CB933902, National Natural Science Foundation for youth No. 81100371, Natural Science Foundation of Jiangsu Province No. BK2011308, Universities Natural Science Foundation of Jiangsu Province No. $11 \mathrm{KJB} 320014$ and Talent's subsidy project in science and education of department of public health of Suzhou City No. SWKQ1020. Medical innovation team and leading talent of jiangsu Province. No. LJ201126.

\section{Author details}

'Department of Hematology and Oncology, Children's Hospital of Soochow University, Suzhou, 215003, China. ${ }^{2}$ State Key Laboratory of Molecular Oncology, Cancer Institute (Hospital), Peking Union Medical College, Chinese Academy of Medical Sciences, Beijing 100021, China. ${ }^{3}$ Hillman Cancer Center Lab, Department of Pathology, Pittsburgh University, G21 5117 Center Ave. Pittsburgh, PA 15206, USA. ${ }^{4}$ Laboratory of Cellular Oncology, National Cancer Institute, NIH, Building 37, Room 4112, Bethesda, MD 20892, USA. Institute of Clinical Medical Science, China-Japan Friendship Hospital, Beijing, China. ${ }^{6}$ Translational Research Center, Chang Hai Hospital, the Second Military Medical University, Shanghai, China. 'Translational Research Center, Second Hospital, The Second Clinical School, Nanjing Medical University, Nanjing, China.

\section{Authors' contributions}

PJ, SLC, TYF and ZZ performed the most of the experiments. LYP, LL, WJ, ZXM, WSY, ZYL, HSY, ZWL and FX coordinated data collection and quality control, and assisted in the interpretation of results. DXL participated in acquiring laboratory data analysis. NJ and LGL participated in study design and coordination, data analysis and interpretation and drafted the manuscript. All authors read and approved the final manuscript.

\section{Competing interests}

The authors declare that they have no competing interests.
Received: 20 July 2011 Accepted: 8 December 2011

Published: 8 December 2011

\section{References}

1. Carey LA: Through a glass darkly: advances in understanding breast cancer biology, 2000-2010. Clin Breast Cancer 10:188-195.

2. Jensen JD, Knoop A, Ewertz M, Laenkholm AV: ER, HER2, and TOP2A expression in primary tumor, synchronous axillary nodes, and asynchronous metastases in breast cancer. Breast Cancer Res Treat

3. Coradini D, Daidone MG: Biomolecular prognostic factors in breast cancer. Curr Opin Obstet Gynecol 2004, 16:49-55.

4. Hayashi N, Nakamura S, Tokuda Y, Shimoda Y, Yagata H, Yoshida A, Ota H, Hortobagyi GN, Cristofanilli M, Ueno NT: Prognostic value of HER2-positive circulating tumor cells in patients with metastatic breast cancer. Int $J$ Clin Oncol.

5. Hynes NE, Lane HA: ERBB receptors and cancer: the complexity of targeted inhibitors. Nat Rev Cancer 2005, 5:341-354.

6. Goldhirsch A, Wood WC, Gelber RD, Coates AS, Thurlimann B, Senn HJ: Meeting highlights: updated international expert consensus on the primary therapy of early breast cancer. J Clin Oncol 2003, 21:3357-3365.

7. Vichapat V, Gillett C, Fentiman IS, Tutt A, Holmberg L, Luchtenborg M: Risk factors for metachronous contralateral breast cancer suggest two aetiological pathways. Eur $J$ Cancer .

8. Tot T, Gere M, Pekar G, Tarjan M, Hofmeyer S, Hellberg D, Lindquist D, Chen TH, Yen AM, Chiu SY, Tabar L: Breast cancer multifocality, disease extent, and survival. Hum Pathol .

9. Maric P, Ozretic P, Levanat S, Oreskovic S, Antunac K, Beketic-Oreskovic L: Tumor markers in breast cancer-evaluation of their clinical usefulness. Coll Antropol 35:241-247.

10. Wellman G: Breast cancer awareness and survivorship. S D Med 64:157.

11. Jauhiainen M, Monkkonen H, Raikkonen J, Monkkonen J, Auriola S: Analysis of endogenous ATP analogs and mevalonate pathway metabolites in cancer cell cultures using liquid chromatography-electrospray ionization mass spectrometry. J Chromatogr B Analyt Technol Biomed Life Sci 2009, 877:2967-2975.

12. Ran Y, Pan J, Hu H, Zhou Z, Sun L, Peng L, Yu L, Sun L, Liu J, Yang Z: A novel role for tissue factor pathway inhibitor- 2 in the therapy of human esophageal carcinoma. Hum Gene Ther 2009, 20:41-49.

13. von Ballmoos C, Wiedenmann A, Dimroth P: Essentials for ATP synthesis by F1F0 ATP synthases. Annu Rev Biochem 2009, 78:649-672.

14. Rees DM, Leslie AG, Walker JE: The structure of the membrane extrinsic region of bovine ATP synthase. Proc Natl Acad Sci USA 2009, 106:21597-21601.

15. Champagne E, Martinez LO, Collet X, Barbaras R: Ecto-F1Fo ATP synthase/ F1 ATPase: metabolic and immunological functions. Curr Opin Lipidol 2006, 17:279-284.

16. Chi SL, Wahl ML, Mowery YM, Shan S, Mukhopadhyay S, Hilderbrand SC, Kenan DJ, Lipes BD, Johnson CE, Marusich MF, et al: Angiostatin-like activity of a monoclonal antibody to the catalytic subunit of F1F0 ATP synthase. Cancer Res 2007, 67:4716-4724.

17. Moser TL, Stack MS, Asplin I, Enghild JJ, Hojrup P, Everitt L, Hubchak S, Schnaper HW, Pizzo SV: Angiostatin binds ATP synthase on the surface of human endothelial cells. Proc Natl Acad Sci USA 1999, 96:2811-2816.

18. Malaval C, Laffargue M, Barbaras R, Rolland C, Peres C, Champagne E, Perret B, Terce F, Collet X, Martinez LO: RhoA/ROCK I signalling downstream of the P2Y13 ADP-receptor controls HDL endocytosis in human hepatocytes. Cell Signal 2009, 21:120-127.

19. Vantourout P, Martinez LO, Fabre A, Collet X, Champagne E: Ecto-F1ATPase and MHC-class I close association on cell membranes. Mol Immunol 2008, 45:485-492.

20. Das B, Mondragon MO, Sadeghian M, Hatcher VB, Norin AJ: A novel ligand in lymphocyte-mediated cytotoxicity: expression of the beta subunit of $\mathrm{H}+$ transporting ATP synthase on the surface of tumor cell lines. J Exp Med 1994, 180:273-281.

21. Sergeant N, Wattez A, Galvan-valencia M, Ghestem A, David JP, Lemoine J, Sautiere PE, Dachary J, Mazat JP, Michalski JC, et al: Association of ATP synthase alpha-chain with neurofibrillary degeneration in Alzheimer's disease. Neuroscience 2003, 117:293-303.

22. Jian P, Li ZW, Fang TY, Jian W, Zhuan Z, Mei LX, Yan WS, Jian N: Retinoic acid induces $\mathrm{HL}-60$ cell differentiation via the upregulation of miR-663. $J$ Hematol Oncol 4:20. 
23. Jian P, Yanfang T, Zhuan Z, Jian W, Xueming Z, Jian N: MMP28 (epilysin) as a novel promoter of invasion and metastasis in gastric cancer. BMC Cancer 11:200.

24. Papathanassiu AE, MacDonald NJ, Bencsura A, Vu HA: F1F0-ATP synthase functions as a co-chaperone of Hsp90-substrate protein complexes. Biochem Biophys Res Commun 2006, 345:419-429.

25. Pan J, Hu H, Zhou Z, Sun L, Peng L, Yu L, Sun L, Liu J, Yang Z, Ran Y: Tumor-suppressive mir-663 gene induces mitotic catastrophe growth arrest in human gastric cancer cells. Oncol Rep 24:105-112.

26. Zhang X, Gao F, Yu LL, Peng Y, Liu HH, Liu JY, Yin M, Ni J: Dual functions of a monoclonal antibody against cell surface F1F0 ATP synthase on both HUVEC and tumor cells. Acta Pharmacol Sin 2008, 29:942-950.

27. Rhodes DR, Yu J, Shanker K, Deshpande N, Varambally R, Ghosh D, Barrette T, Pandey A, Chinnaiyan AM: ONCOMINE: a cancer microarray database and integrated data-mining platform. Neoplasia 2004, 6:1-6.

28. Montel V, Huang TY, Mose E, Pestonjamasp K, Tarin D: Expression profiling of primary tumors and matched lymphatic and lung metastases in a xenogeneic breast cancer model. Am J Pathol 2005, 166:1565-1579.

29. Talbot JC, Dautant A, Polidori A, Pucci B, Cohen-Bouhacina T, Maali A, Salin B, Brethes D, Velours J, Giraud MF: Hydrogenated and fluorinated surfactants derived from Tris(hydroxymethyl)-acrylamidomethane allow the purification of a highly active yeast F1-F0 ATP-synthase with an enhanced stability. J Bioenerg Biomembr 2009, 41:349-360.

30. Saum R, Schlegel K, Meyer B, Muller V: The F1FO ATP synthase genes in Methanosarcina acetivorans are dispensable for growth and ATP synthesis. FEMS Microbiol Lett 2009, 300:230-236.

31. Mitrofan LM, Pelkonen J, Monkkonen J: The level of ATP analog and isopentenyl pyrophosphate correlates with zoledronic acid-induced apoptosis in cancer cells in vitro. Bone 2009, 45:1153-1160.

32. Smallbone K, Gavaghan DJ, Gatenby RA, Maini PK: The role of acidity in solid tumour growth and invasion. J Theor Biol 2005, 235:476-484.

33. Lu ZJ, Song QF, Jiang SS, Song Q, Wang W, Zhang GH, Kan B, Chen LJ, Yang $J$, LuO F, et al: Identification of ATP synthase beta subunit (ATPB) on the cell surface as a non-small cell lung cancer (NSCLC) associated antigen. BMC Cancer 2009, 9:16.

34. Martin B, Aragues R, Sanz R, Oliva B, Boluda S, Martinez A, Sierra A: Biological pathways contributing to organ-specific phenotype of brain metastatic cells. J Proteome Res 2008, 7:908-920.

35. Radojkovic C, Genoux A, Pons V, Combes G, de Jonge H, Champagne E, Rolland C, Perret B, Collet X, Terce F, Martinez LO: Stimulation of cell surface F1-ATPase activity by apolipoprotein A-I inhibits endothelial cell apoptosis and promotes proliferation. Arterioscler Thromb Vasc Biol 2009, 29:1125-1130.

36. Chi SL, Pizzo SV: Angiostatin is directly cytotoxic to tumor cells at low extracellular pH: a mechanism dependent on cell surface-associated ATP synthase. Cancer Res 2006, 66:875-882.

37. Wang J, Han Y, Liang J, Cheng X, Yan L, Wang Y, Liu J, Luo G, Chen X, Zhao $L$, et al: Effect of a novel inhibitory $m A b$ against beta-subunit of F1F0 ATPase on HCC. Cancer Biol Ther 2008, 7:1829-1835.

38. Abstracts. Pacing Clin Electrophysio/ 34:1307-1451.

doi:10.1186/1479-5876-9-211

Cite this article as: Pan et al:: ATP synthase ecto- $\alpha$-subunit: a novel therapeutic target for breast cancer. Journal of Translational Medicine 2011 9:211.

\section{Submit your next manuscript to BioMed Central and take full advantage of:}

- Convenient online submission

- Thorough peer review

- No space constraints or color figure charges

- Immediate publication on acceptance

- Inclusion in PubMed, CAS, Scopus and Google Scholar

- Research which is freely available for redistribution 